\title{
Grain Boundary Segregation and Interdiffusion Effects in Nickel-Copper Alloys: An Effective Means to Improve the Thermal Stability of Nanocrystalline Nickel
}

\author{
Eva Pellicer, ${ }^{*}+$ Aïda Varea, ${ }^{\dagger}$ Kartik M. Sivaraman, ${ }^{\dagger}$ Salvador Pané, ${ }^{\ddagger}$ Santiago Suriñach, ${ }^{\dagger}$ Maria Dolors Baró, ${ }^{\dagger}$ \\ Josep Nogués, ${ }^{\S, \perp}$ Bradley J. Nelson, ${ }^{\neq}$and Jordi Sort ${ }^{*,+, \S}$ \\ ${ }^{\dagger}$ Departament de Física and ${ }^{\perp}$ Catalan Institute of Nanotechnology (ICN) and CIN2, Universitat Autònoma de Barcelona, \\ E-08193 Bellaterra, Barcelona, Spain \\ ${ }^{\ddagger}$ Institute of Robotics and Intelligent Systems (IRIS), ETH Zurich, CH-8092 Zurich, Switzerland

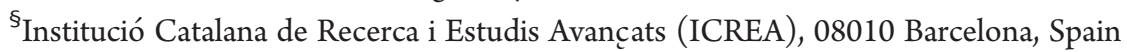 \\ Supporting Information
}

ABSTRACT: Nanocrystalline $(n c)$ Ni films show pronounced grain growth and suffer from concomitant deterioration of their mechanical and magnetic properties after annealing at relatively low temperatures $\left(T_{\mathrm{ANN}} \geq 475 \mathrm{~K}\right)$. This constitutes a drawback for their applicability as coatings or in components of miniaturized devices. This work reveals that the thermal stability of $n c \mathrm{Ni}$ is significantly improved by controllably alloying $\mathrm{Ni}$ with $\mathrm{Cu}$, by means of electrodeposition, to form a $\mathrm{Ni}_{1-x} \mathrm{Cu}_{x}$ solid solution. To tune the composition of such $n c$ alloys, $\mathrm{Ni}_{1-x} \mathrm{Cu}_{x}$ films are deposited galvanostatically using an electrolytic bath containing $\mathrm{Ni}$ and $\mathrm{Cu}$ sulfate salts as electroactive species, saccharine as grain-refining agent, and applying current densities ranging from -10 to $-40 \mathrm{~mA} \mathrm{~cm}{ }^{-2}$. The enhanced thermal stability is ascribed to segregation of a Cu-rich phase at the $\mathrm{Ni}_{1-x} \mathrm{Cu}_{x}$ grain boundaries, which acts as a shielding layer against grain growth. As a result, high values of hardness (in

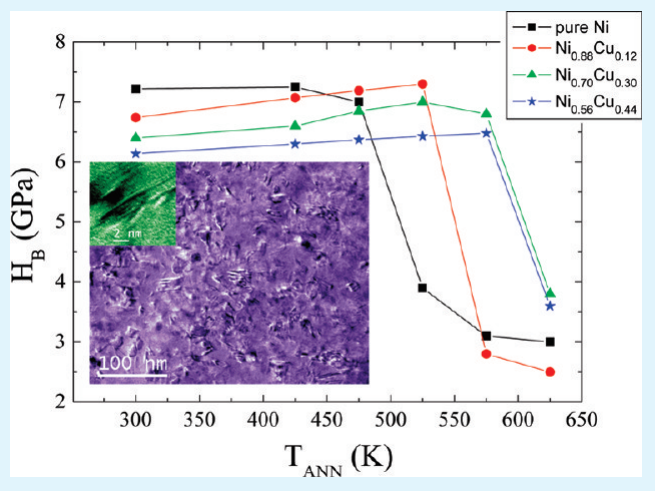
excess of $6 \mathrm{GPa}$ ) remain in $n c \mathrm{Ni}_{1-x} \mathrm{Cu}_{x}$ for $x \geq 0.3$, even after annealing at $T_{\mathrm{ANN}} \geq 575 \mathrm{~K}$. From a magnetic point of view, $\mathrm{Ni}_{1-x} \mathrm{Cu}_{x}$ films possess lower coercivity values than pure $n c \mathrm{Ni}$ films, both in the as-prepared and annealed states, thus offering potential advantages for certain soft magnetic applications.

KEYWORDS: nickel-copper alloy, electrodeposition, nanocrystalline, thermal stability, hardness, magnetic properties

\section{INTRODUCTION}

Nanocrystalline $(n c)$ metallic films are known to benefit from enhanced, and sometimes novel, physical and chemical properties as compared to conventional coarse-grained films. ${ }^{1-4}$ Indeed, a reduction of the crystallite size toward the sub-100 nm scale results in larger hardness values, increased ductility and fatigue behavior, better wear resistance, enhanced coercivity, and eventually, higher resistance to pitting corrosion. These properties make $n c$ films technologically appealing for the implementation of a wide range of components in micro/nanoelectromechanical systems (MEMS/NEMS) or to obtain mechanically hard, corrosion-resistant coatings. ${ }^{5-7}$

In spite of these outstanding properties, $n c$ metals typically show relatively poor thermal stability. ${ }^{8,9}$ Grain growth occurs in these materials at relatively low homologous temperatures (often less than $50 \%$ of the melting temperature), mainly because of the large amounts of metastable grain boundaries and defects, where enhanced atomic diffusivity is promoted. As a result, the use of $n c$ materials in applications such as cutting and friction tools, thermal and diffusion barriers, high-temperature catalysts, emission and filter components, jet engines or stampers for compact disk manufacturing remains rather challenging. In particular, poor thermal stability constitutes a real technological drawback in miniaturized devices, where temperature can locally raise significantly because heat dissipation is precluded as compared to bulk materials. In this case, grain coarsening can lead to loss of geometrical fidelity, in addition to the decrease in mechanical strength. Moreover, some lithographic methods used to fabricate small components in MEMS/NEMS also require a few heating steps, such as baking or thermal curing, which can easily deteriorate the properties of $n c$ metallic films.

For all these reasons, several strategies have been designed in recent years to improve the thermal stability of $n c$ metals. These include, among others, grain boundary pinning (using solute atoms, fine particles-oxide or nitride phases-or porosity), control of compressive residual stresses, induced interfacial phase transformations or tuning of the chemical ordering at grain boundaries. $^{1,8,9}$ Alloying with certain specific elements can have a

Received: January 20, 2011

Accepted: June 13, 2011 
beneficial effect on preserving the $n c$ character of a material, particularly when segregation of one of the constituent elements to the grain boundaries occurs during annealing (such as in $\mathrm{Ni}-\mathrm{P}, \mathrm{Fe}-\mathrm{Zr}, \mathrm{Pd}-\mathrm{Zr}, \mathrm{Ru}-\mathrm{Al}, \mathrm{Y}-\mathrm{Fe}$, or $\mathrm{Ni}-\mathrm{Mn}$ ), thus reducing the total Gibbs free energy of the system. ${ }^{8-15}$ This effect is particularly exacerbated in alloys composed of elements with a large positive enthalpy of mixing, like $\mathrm{Fe}-\mathrm{Ag}$ or $\mathrm{Fe}-\mathrm{Cu}^{1,16,17}$ Because of grain boundary segregation, the $n c$ structure can be either kinetically or thermodynamically stabilized. Kinetic stabilization is accomplished when the grain boundary velocity is reduced during thermal annealing (e.g., by solute drag mechanism). ${ }^{9,11}, 14,18$ Besides, in some systems (e.g., $\mathrm{Fe}-\mathrm{Zr}$, $\mathrm{Ni}-\mathrm{W}$ ), $n c$ structures are thermodynamically favored because alloying causes a significant reduction in the grain boundary energy and hence decreases the associated driving force for grain growth. ${ }^{10,11,19}$

Among the numerous techniques to grow metallic films, electrodeposition stands out from the rest because it relies on a simple, relatively low-cost and user-friendly setup, it allows fast deposition rates (thus being much less time-consuming than physical methods like sputtering or electron beam evaporation), it does not require vacuum technology and deposition can be performed onto a wide variety of substrate shapes, not necessarily flat. ${ }^{20}$ It is noteworthy that conventional physical deposition methods are generally limited to the growth of thin films (up to $1-2 \mu \mathrm{m}$ ), a restriction that can be disadvantageous for some MEMS/NEMS, where thicker patterned features are required.

Remarkably, electrodeposition is particularly suitable to prepare $n c$ metals virtually free of porosity. This can be achieved by adding grain-refining agents (e.g., saccharine, coumarine or polyethylenglycol) to the electrolytic bath or by depositing under pulse-plating mode. ${ }^{21}$ Such direct growth of $n c$ metallic material circumvents the problem of other manufacturing techniques where the $n c$ metals are obtained by high-temperature consolidation of $n c$ powder precursors, during which a certain degree of grain coarsening unavoidably occurs. Furthermore, electrodeposition is not limited to the growth of films or sheets composed of single metallic elements. In fact, several alloys (e.g., Co-Pt, $\mathrm{Co}-\mathrm{Ni}, \mathrm{Ni}-\mathrm{W}, \mathrm{Co}-\mathrm{Fe}-\mathrm{Ni}, \mathrm{Co}-\mathrm{Mo}, \mathrm{Ca}-\mathrm{P}$, etc.) can be easily electroplated for assorted purposes ${ }^{22-28}$ and, as aforementioned, this can be advantageous in terms of enhancing the thermal stability of the obtained materials. There are various parameters that allow precise tuning of the alloy composition: bath formulation and temperature, applied current density/overpotential, hydrodynamic regime, etc. For instance, in citrate-containing electrolytic solutions, deposition of some metals (like $\mathrm{Cu}$ ) is mass-transfer-controlled, whereas that of other metals (like $\mathrm{Ni}$ ) is charge-transfer-controlled. Hence, by decreasing the current density, Ni deposition can be enhanced while the concentration of electroactive $\mathrm{Cu}$ species at the electrolyte/working-electrode interface becomes depleted, thus providing a means to obtain $\mathrm{Ni}-\mathrm{Cu}$ films with controllable composition. ${ }^{29}$ It should be noted that $\mathrm{Ni}-\mathrm{Cu}$ alloys with tunable stoichiometry have been prepared recently by means of alcohol-assisted chemical vapor deposition. ${ }^{30}$

Because of their soft magnetic character, $\mathrm{Ni}$ and some $\mathrm{Ni}$ alloys (like $\mathrm{Co}-\mathrm{Ni}$ or $\mathrm{Ni}_{19} \mathrm{Fe}_{81}$, i.e., permalloy) are among the most widely used materials to manufacture remotely actuated magnetic MEMS/NEMS. ${ }^{31}$ In spite of their good magnetic properties, the mechanical behavior of these films is typically worse than those of conventional materials employed in MEMS/ NEMS (like $\mathrm{Si}, \mathrm{SiN}$ or $\mathrm{SiC}$ ). For this reason, it is important to grow these metallic films in $n c$ form and to preserve the $n c$ structure after remaining at intermediate temperatures (i.e., at the working conditions).

Herein, the effects of alloying $\mathrm{Ni}$ with $\mathrm{Cu}$ on the thermal stability (grain size, microstrains, cell parameter, stacking faults) and the resulting properties of electroplated $\mathrm{Ni}_{1-\mathrm{x}} \mathrm{Cu}_{x}(0 \leq x \leq$ 0.44) $n c$ films are investigated. The results show that, for sufficiently large $\mathrm{x}$ values, segregation of a $\mathrm{Cu}$-rich phase at grain boundaries occurs during annealing, preceding grain coarsening. Because the enthalpy of mixing between $\mathrm{Cu}$ and $\mathrm{Ni}$ is positive, the $\mathrm{Cu}$-rich phase acts as a pinning layer against thermally activated grain growth, thus enhancing the thermal stability of these films and improving some of their mechanical and magnetic properties with respect to pure $\mathrm{Ni}$.

\section{EXPERIMENTAL METHODS}

The metallic films were obtained by direct current electrodeposition in one-compartment thermostatized three-electrode cell using a PGSTAT30 Autolab potentiostat/galvanostat (Ecochemie). The electrolytic solutions were prepared from analytical grade reagents and Milipore Milli-Q water. Ni films were obtained from an electrolyte containing $190 \mathrm{~g} / \mathrm{L} \mathrm{NiSO}_{4} \cdot 6 \mathrm{H}_{2} \mathrm{O}$ (nickel sulfate), $87 \mathrm{~g} / \mathrm{L} \mathrm{Na}_{3} \mathrm{C}_{6} \mathrm{H}_{5} \mathrm{O}_{7}$. $2 \mathrm{H}_{2} \mathrm{O}$ (sodium citrate), $0.2 \mathrm{~g} / \mathrm{L} \mathrm{NaC}_{12} \mathrm{H}_{25} \mathrm{SO}_{4}$ (sodium dodecylsulphate) and $0.5 \mathrm{~g} / \mathrm{L} \mathrm{C}_{7} \mathrm{H}_{5} \mathrm{NO}_{3} \mathrm{~S}$ (saccharine). $\mathrm{Ni}-\mathrm{Cu}$ alloy films were deposited from an electrolyte containing the same chemicals except for the metal salts: $184 \mathrm{~g} / \mathrm{L} \mathrm{NiSO}{ }_{4} \cdot 6 \mathrm{H}_{2} \mathrm{O}, 6.24 \mathrm{~g} / \mathrm{L} \mathrm{CuSO}{ }_{4} \cdot 5 \mathrm{H}_{2} \mathrm{O}$ (copper sulfate). Hence, both, pure $\mathrm{Ni}$ and $\mathrm{Ni}-\mathrm{Cu}$ films were obtained using analogous bath formulation. The electrolyte volume was $100 \mathrm{~mL}$. The $\mathrm{pH}$ was fixed at 4.5 and the temperature at $30^{\circ} \mathrm{C}$ in all cases. Silicon (100) substrates with e-beam evaporated $\mathrm{Ti}(100 \mathrm{~nm}) / \mathrm{Cu}(500 \mathrm{~nm})$ adhesion/seed layers were used as working electrodes, which were positioned vertically within the electrolyte. The working area was $6 \times$ $5 \mathrm{~mm}^{2}$. A double junction $\mathrm{Ag} \mid \mathrm{AgCl}(\mathrm{E}=+0.210 \mathrm{~V} / \mathrm{SHE})$ reference electrode (Metrohm AG) was used with $3 \mathrm{M} \mathrm{KCl}$ inner solution and an interchangeable outer solution made of $1 \mathrm{M} \mathrm{Na}_{2} \mathrm{SO}_{4}$. A platinum spiral served as counter electrode. Prior to deposition, the copper surface was first degreased with acetone followed by washing in isopropyl alcohol and water and, finally, dipped in diluted sulphuric acid to remove any oxides and organic residues present on the copper surface. The backside of the silicon substrate was insulated to ensure that only the copper surface was conductive. Before each deposition, the electrolyte was deaerated with nitrogen gas and a blanket of nitrogen was maintained on top of the solution during the experiment. Deposition was conducted galvanostatically, by applying a constant current density in the range from -10 to $-40 \mathrm{~mA} \mathrm{~cm}^{-2}$, under mild stirring (200 rpm) using a magnetic stirrer bar. The electrical charge was adjusted across all depositions to attain similar film thicknesses. After deposition, the films were thoroughly rinsed in water and stored in air. The chemical composition of the films was determined by energy dispersive X-ray spectroscopy (EDXS). Metal proportions are expressed in atomic percentage (at \%). The impurity contents (e.g., sulfur and carbon) determined by chemical analyses were below $0.1 \mathrm{wt} \%$ in all samples. From four-point measurements using interferometric profilometry, the average film thickness was determined to be around $3 \mu \mathrm{m}$ for all the investigated electroplated alloys.

To prevent oxidation, annealing treatments of the as-deposited films were performed under high vacuum $\left(p<1 \times 10^{-5} \mathrm{mbar}\right)$ at temperatures, $T_{\mathrm{ANN}}$, ranging from 425 to $625 \mathrm{~K}$. The samples were heated at $5 \mathrm{~K} / \mathrm{min}$ and cooled down to room temperature after keeping them at $T_{\text {ANN }}$ for $3 \mathrm{~h}$. The structure of the deposits, both before and after annealing, was studied by X-ray diffraction (XRD) and transmission electron microscopy (TEM). XRD patterns were recorded on a Philips X'Pert diffractometer using the $\mathrm{Cu} \mathrm{K}_{\alpha}$ radiation in the $40-55^{\circ} 2 \theta$ range 

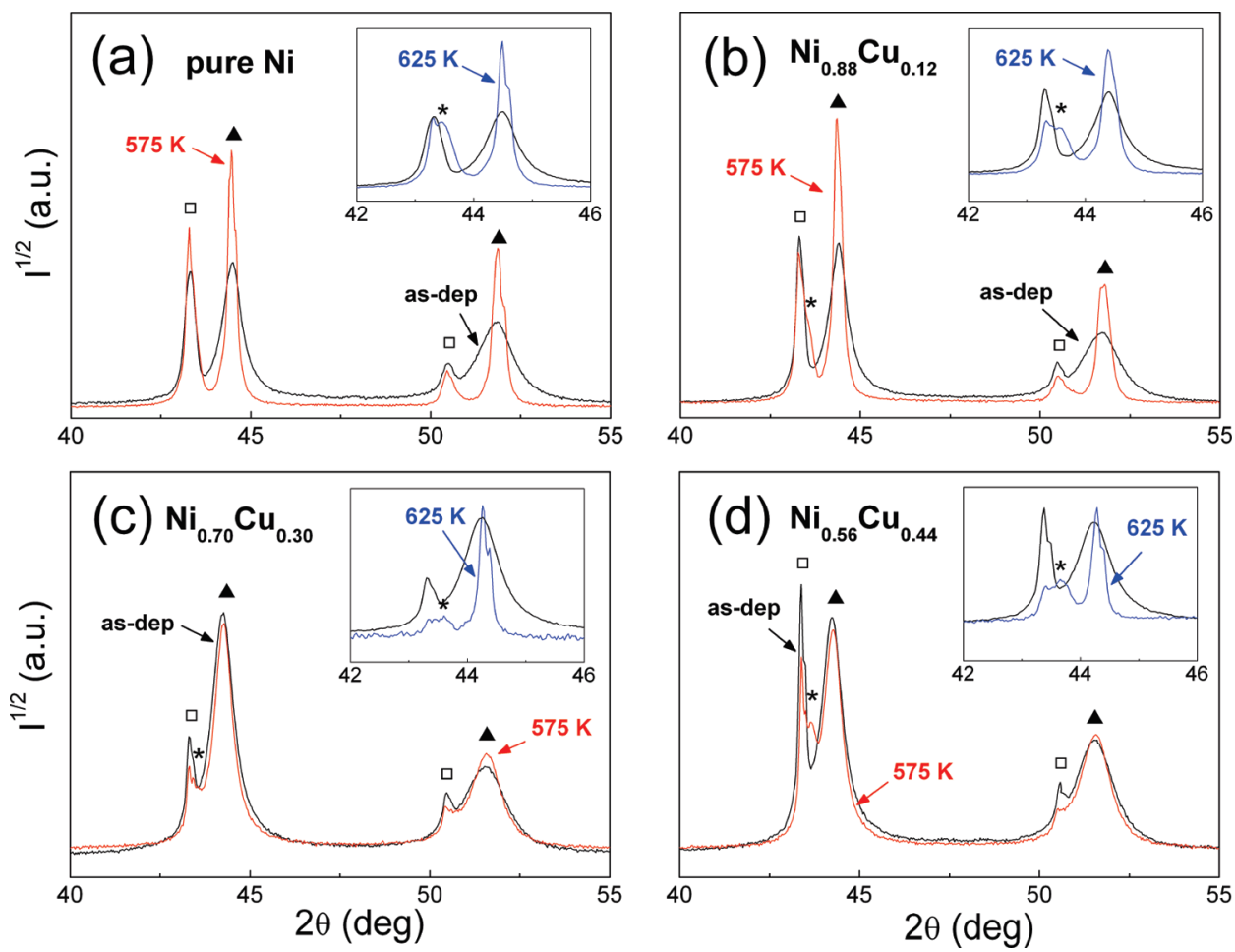

Figure 1. X-ray diffraction (XRD) patterns, in the 40-55 $2 \theta$ range, of (a) pure $\mathrm{Ni}$, (b) $\mathrm{Ni}_{0.88} \mathrm{Cu}_{0.12},(\mathrm{c}) \mathrm{Ni}_{0.70} \mathrm{Cu}_{0.30}$, and (d) $\mathrm{Ni}_{0.56} \mathrm{Cu}_{0.44}$ films in the as-deposited states (in black) and after annealing at $T_{\mathrm{ANN}}=575 \mathrm{~K}$ (in red). Indicated with the symbols $\square$, $\mathbf{\Lambda}$, and ${ }^{*}$ are the XRD peaks corresponding to the $\mathrm{Cu}$ seed layer, the $\mathrm{Ni}_{1-x} \mathrm{Cu}_{x}$ film and a Cu-rich phase that forms during annealing. Shown in the insets are enlargements of the (111) XRD peaks of the as-deposited films (in black) and the films annealed at $T_{\mathrm{ANN}}=625 \mathrm{~K}$ (in blue). Note that pronounced XRD peak narrowing (i.e., grain growth and microstrain release) occurs in pure $\mathrm{Ni}$ and $\mathrm{Ni}_{0.88} \mathrm{Cu}_{0.12}$ films already at $T_{\mathrm{ANN}}=575 \mathrm{~K}$. Conversely, for the films containing larger Cu percentages, a clear decrease in the peak width is only observed at higher temperatures $\left(T_{\mathrm{ANN}}=625 \mathrm{~K}\right)$.

$\left(0.03^{\circ}\right.$ step size, $10 \mathrm{~s}$ holding time $)$. The global structural parameters, such as cell parameter, $a$, crystallite size, $\langle D\rangle$ (defined here as the average coherently diffracting domain sizes), and microstrains or atomic level deformations, $\left\langle\varepsilon^{2}\right\rangle^{1 / 2}$, were evaluated by fitting the full XRD patterns using the Materials Analysis Using Diffraction (MAUD) Rietveld refinement program. ${ }^{32,33}$ This software includes an algorithm to quantitatively evaluate the stacking fault probability, $\alpha_{\mathrm{SF}}$ (in which $1 / \alpha_{\mathrm{SF}}$ indicates the average number of atomic planes between two consecutive stacking faults). ${ }^{34}$ TEM characterization was carried out on a JEOL JEM2011 microscope operated at $200 \mathrm{kV}$. For the TEM observations (planar views), the films were thinned by ion milling, which was performed from both sides of the film in order to remove the seed layer and any surface contamination. Electron energy loss spectroscopy (EELS) analysis was also carried out after annealing at $625 \mathrm{~K}$ in order to assess the $\mathrm{Cu} / \mathrm{Ni}$ proportion both inside and across grain boundaries (i.e., to probe thermally induced atomic segregation). The EELS experiments were performed using a JEOL JEM 2010F TEM, operated at $200 \mathrm{kV}$, with a spot size of $0.5 \mathrm{~nm}$.

The hardness and reduced Young's modulus of the films, before and after annealing, were evaluated by nanoindentation, operating in the load control mode, using an UMIS device from Fischer-Cripps Laboratories equipped with a Berkovich pyramidal-shaped diamond tip. The value of maximum applied force was chosen to be $10 \mathrm{mN}$ to ensure that the maximum penetration depth during the tests was kept below one tenth of the overall film thickness. This is considered as a necessary condition to avoid having an influence of the substrate on the measured mechanical properties of the film. ${ }^{35}$ The thermal drift during nanoindentation was kept below $0.05 \mathrm{~nm} / \mathrm{s}$. Proper corrections for the contact area (calibrated with a fused quartz specimen), instrument compliance, and initial penetration depth were applied. The Berkovich indentation hardness values, $H_{\mathrm{B}}$, were derived from the load-displacement curves at the beginning of the unloading segment using the method of Oliver and Pharr. ${ }^{36}$ The room-temperature magnetic properties were locally assessed by magneto-optic Kerr effect (MOKE) magnetometry (Durham magneto-optics) with a maximum in-plane applied field of 400 Oe. Note that MOKE is a surface-sensitive technique, which senses penetration depths of the order of a few tens of $\mathrm{nm}$. Hence, the obtained Kerr signal is proportional to the saturation magnetization of the sample surface.

\section{RESULTS AND DISCUSSION}

Structural Evolution during Thermal Annealing. The X-ray diffraction (XRD) patterns of the $\mathrm{Ni}_{1-\mathrm{x}} \mathrm{Cu}_{x}$ films, measured both in the as-deposited state and after annealing at $T_{\mathrm{ANN}}=575$ and $625 \mathrm{~K}$, are shown in Figure 1. Broad diffraction peaks are observed in the as-deposited films, matching the angular positions of face-centered cubic (fcc) copper (seed-layer) and fcc $\mathrm{Cu}-\mathrm{Ni}$ phases. The Rietveld analysis of the XRD data evidence that, before annealing, the crystallite size, $\langle\mathrm{D}\rangle$, ranges from 30 to $40 \mathrm{~nm}$, irrespective of the exact film composition (see Figure 2). Values of microstrains, $\left\langle\varepsilon^{2}\right\rangle^{1 / 2}$, around $1 \times 10^{-3}$ are obtained, which are lower than in $n c$ materials typically obtained by severe plastic deformation techniques. ${ }^{37}$ The small values of $\langle\mathrm{D}\rangle$ and $\left\langle\varepsilon^{2}\right\rangle^{1 / 2}$ can be ascribed to the crystal size refinement and stress relieve activity promoted by the saccharine. Note that, in general, smaller crystallite sizes would be expected for higher current densities (i.e., smaller $\mathrm{Cu}$ contents). As this trend was not observed here, the effect of saccharine likely dominates over any possible influence of the current density. 

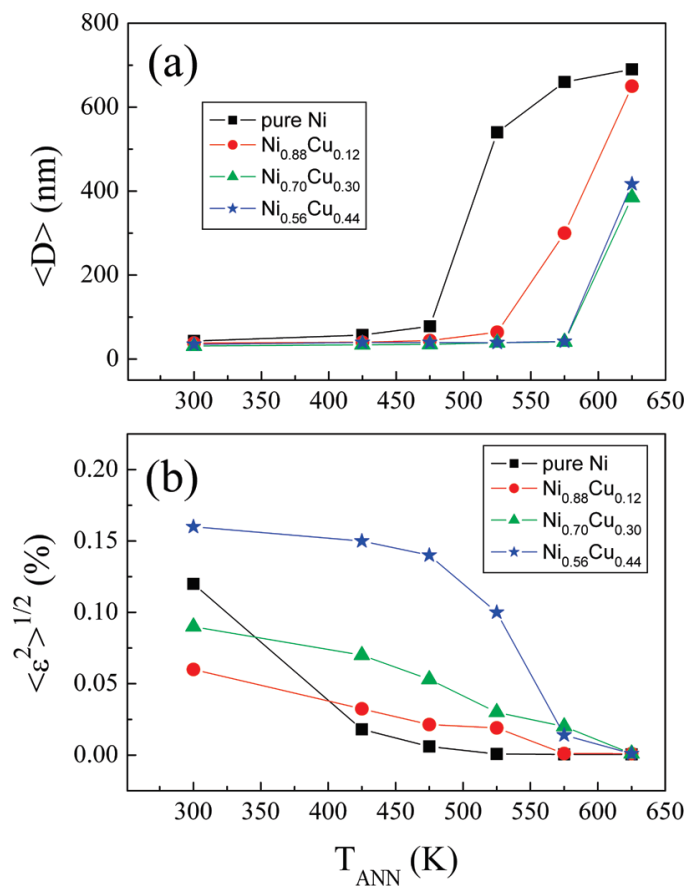

Figure 2. Dependence of (a) the crystallite size, $\langle D\rangle$, and (b) the microstrains, $\left\langle\varepsilon^{2}\right\rangle^{1 / 2}$, on the annealing temperature, $\mathrm{T}_{\mathrm{ANN}}$, for pure $\mathrm{Ni}$ (black square), $\mathrm{Ni}_{0.88} \mathrm{Cu}_{0.12}$ (red circle), $\mathrm{Ni}_{0.70} \mathrm{Cu}_{0.30}$ (green triangle), and $\mathrm{Ni}_{0.56} \mathrm{Cu}_{0.44}$ (blue star) films. Pronounced grain growth occurs in pure $\mathrm{Ni}$ around $T_{\mathrm{ANN}}=500 \mathrm{~K}$, whereas for $\mathrm{Ni}_{0.70} \mathrm{Cu}_{0.30}$ and $\mathrm{Ni}_{0.56} \mathrm{Cu}_{0.44}$ films, significant grain coarsening occurs around $T_{\mathrm{ANN}}=600 \mathrm{~K}$. A progressive decrease of $\left\langle\varepsilon^{2}\right\rangle^{1 / 2}$ with $T_{\text {ANN }}$ is observed for all compositions, although $\left\langle\varepsilon^{2}\right\rangle^{1 / 2}$ decreases earlier for pure $\mathrm{Ni}$ and the reduction seems to be delayed for the $\mathrm{Ni}_{0.56} \mathrm{Cu}_{0.44}$ film. Note that error bars would be included within the size of the symbols.

As shown in Figure 2, the crystallite size remains below $100 \mathrm{~nm}$ in the entire compositional range for $T_{\text {ANN }} \leq 475 \mathrm{~K}$. Remarkably, pronounced grain coarsening occurs in Ni films at $T_{\mathrm{ANN}}=$ $525 \mathrm{~K}$. This is in agreement with the onset temperature for grain growth observed in pure Ni electrodeposits subject to annealing. In fact, several works examined in the past the thermal behavior of $n c \mathrm{Ni}$ films by different means, mainly by differential scanning calorimetry (DSC) and TEM analyses. ${ }^{38-43}$ Abnormal grain growth (leading to the formation of bimodal grain structures) in $n c \mathrm{Ni}$ (with $10-30 \mathrm{~nm}$ grain size) was reported to occur through a quasi-nucleation growth process above $473 \mathrm{~K}^{44} \mathrm{~A}$ broad exothermic band at $c a .373-498 \mathrm{~K}$ followed by a peak at around $543 \mathrm{~K}$ ascribed to pronounced grain growth were determined by DSC measurements. ${ }^{40}$ Conversely, the films with $x=0.30$ and 0.44 do not exhibit obvious thermally induced grain growth until $T_{\text {ANN }} \geq 625 \mathrm{~K}$. This is already evident in Figure 1, where clear narrowing of the XRD peaks occurs for $x=0$ and 0.12 at $575 \mathrm{~K}$, whereas the width of the XRD peaks of $\mathrm{Ni}_{1-x} \mathrm{Cu}_{x}$ films with $\mathrm{x}=0.30$ and 0.44 at $T_{\mathrm{ANN}}=575 \mathrm{~K}$ remains virtually the same as in the as-deposited state. These results reveal that, from a microstructural point of view, alloying $\mathrm{Ni}$ with $\mathrm{Cu}$ significantly enhances the thermal stability of $n c \mathrm{Ni}$ films. In turn, the microstrains tend to be progressively released as $T_{\text {ANN }}$ is increased [see Figure 2 (b)], particularly for samples with low $\mathrm{Cu}$ percentages. Note that the reduction in $\left\langle\varepsilon^{2}\right\rangle^{1 / 2}$ takes place already before the onset temperature for grain growth.
The $40-55^{\circ} 2 \theta$ range, displayed in Figure 1, covers the (111) and (200) XRD reflections, located for $\mathrm{Ni}_{1-x} \mathrm{Cu}_{x}$ around 44 and $52^{\circ}$, respectively. An obvious difference in the width of the (111) and (200) peaks of the as-prepared $\mathrm{Ni}_{1-x} \mathrm{Cu}_{x}$ films is observed. This is indicative of the existence of stacking faults. ${ }^{34}$ The MAUD Rietveld refinement software allows deconvoluting the contributions from crystallite size, microstrains and stacking faults on the XRD peaks width. From the refinements, the stacking fault probability was found to be $\alpha_{\mathrm{SF}} \approx 2 \times 10^{-3}$ for all as-deposited films, suggesting that intragranular growth nanotwins were formed during electroplating. As expected, the values of $\alpha_{\mathrm{SF}}$ were also found to decrease with annealing temperature in the overall investigated compositional range.

Another interesting observation is that small peaks (indicated with an ${ }^{*}$ in Figure 1), located at $2 \theta$ angles between those of $\mathrm{Cu}$ and $\mathrm{Ni}_{1-x} \mathrm{Cu}_{x}$ reflections, appear for $T_{\mathrm{ANN}} \geq$ $525 \mathrm{~K}$. The occurrence of these peaks suggests that a $\mathrm{Cu}$-rich phase is formed when the annealing temperature exceeds 525 $\mathrm{K}$. The origin of this phase could be two-fold: either it forms from interdiffusion between the $\mathrm{Cu}$ seed-layer and the upper $\mathrm{Ni}_{1-x} \mathrm{Cu}_{x}$ films or it arises from thermally induced segregation of $\mathrm{Cu}$ atoms at the grain boundaries present in the $\mathrm{Ni}_{1-\mathrm{x}} \mathrm{Cu}_{x}$ phase. Detailed investigations combining XRD and TEM results suggest that both effects occur simultaneously, although grain boundary segregation starts at a lower $T_{\text {ANN }}$ than interlayer diffusion and is actually enhanced in samples with higher $\mathrm{Cu}$ contents. Indeed, as shown in Figure 1, a progressive decrease in the intensity of the $\mathrm{Cu}$ seed layer peaks is observed as $T_{\mathrm{ANN}}$ is increased. This is particularly obvious for $T_{\text {ANN }}=625 \mathrm{~K}$. Moreover, although no additional peaks emerge at $575 \mathrm{~K}$ in the XRD pattern corresponding to pure $\mathrm{Ni}$, a clear shoulder appears for this film at $T_{\mathrm{ANN}}=625 \mathrm{~K}$ (see panel a in Figure 1), thus corroborating that interdiffusion between the seed-layer and the films unambiguously takes place, at least at $625 \mathrm{~K}$. This progressive decrease in the intensity of the $\mathrm{Cu}$ XRD peaks (and not in the $\mathrm{Ni}_{1-x} \mathrm{Cu}_{x}$ reflections) is in agreement with other works which show that when a diffusion-induced recrystallization layer forms in $\mathrm{NiCu} / \mathrm{Cu}$ couples during annealing, this layer grows mainly toward $\mathrm{Cu}$, which progressively decreases in thickness. ${ }^{45}$

From our results, there is also clear evidence that, besides interlayer diffusion, $\mathrm{Cu}$ segregation toward grain boundaries occurs as well during thermal annealing. Figure 1 shows that the $\mathrm{Ni}-\mathrm{Cu}$ reflections of as-deposited $\mathrm{Ni}_{1-\mathrm{x}} \mathrm{Cu}_{x}$ films are progressively shifted toward lower $2 \theta$ angles as the $\mathrm{Cu}$ percentage is increased, indicating a progressive increase in the cell parameter, $a$ (see Figure 3 ). This is in agreement with the Vegard's law since $a_{\mathrm{Ni}}=0.35238 \mathrm{~nm}$ is smaller than $a_{\mathrm{Cu}}=0.36150 \mathrm{~nm}$. Of course, the $\mathrm{Cu}$ seed-layer peaks are not shifted in angle. Upon annealing, the cell parameter of pure Ni films does not vary. Conversely, for $T_{\text {ANN }} \geq 525 \mathrm{~K}$, the cell parameter for all $\mathrm{Ni}_{1-x} \mathrm{Cu}_{x}$ films (except for $x=0$ ) is found to decrease. This confirms that there is a tendency for grain boundary $\mathrm{Cu}$ segregation as annealing proceeds, which in turn causes $\mathrm{Ni}$ enrichment inside the grains. Actually, $\mathrm{Cu}$ grain boundary segregation in $\mathrm{Ni}-\mathrm{Cu}$ alloys is a well-documented effect and it can occur in bulk alloys, thin films or nanoparticles. ${ }^{46-48}$ However, the role of this effect in stabilizing the $n c$ character of $\mathrm{Ni}$ films has not been so far unravelled. It should be noted that, from the Rietveld refinement of the XRD data, the weight percentage of the $\mathrm{Cu}$-rich phase formed upon annealing is around $15 \%$ and $25 \%$ in $\mathrm{Ni}_{0.70} \mathrm{Cu}_{0.30}$ after annealing at $T_{\mathrm{ANN}}=575$ and $625 \mathrm{~K}$, respectively. For films with lower $\mathrm{Cu}$ 


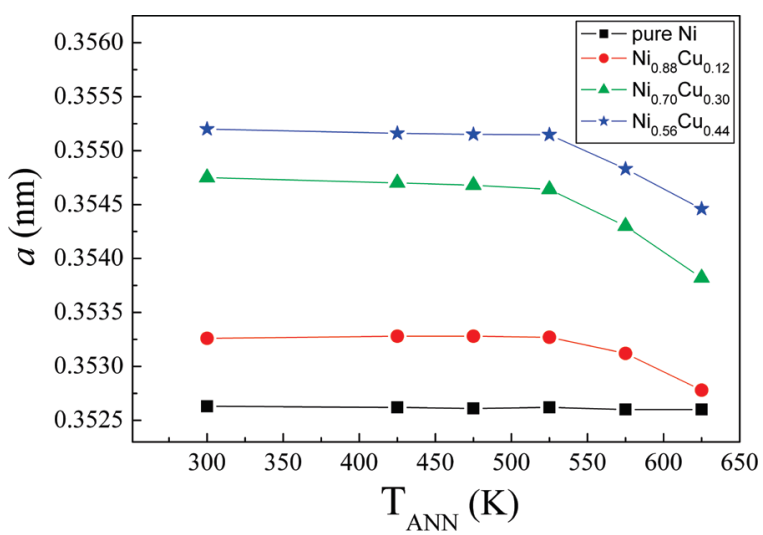

Figure 3. Dependence of the cell parameter, $a$, on the annealing temperature, $\mathrm{T}_{\mathrm{ANN}}$, for pure $\mathrm{Ni}$ (black square), $\mathrm{Ni}_{0.88} \mathrm{Cu}_{0.12}$ (red circle), $\mathrm{Ni}_{0.70} \mathrm{Cu}_{0.30}$ (green triangle), and $\mathrm{Ni}_{0.56} \mathrm{Cu}_{0.44}$ (blue star) films. As expected, larger cell parameter is observed for the alloys containing larger $\mathrm{Cu}$ percentages (in agreement with Vegard's law). Remarkably, a decrease in $a$ is observed in $\mathrm{Ni}_{0.88} \mathrm{Cu}_{0.12}, \mathrm{Ni}_{0.70} \mathrm{Cu}_{0.30}$, and $\mathrm{Ni}_{0.56} \mathrm{Cu}_{0.44}$ films for $T_{\text {ANN }}>525 \mathrm{~K}$. This indicates that the $\mathrm{Ni}_{1-x} \mathrm{Cu}_{x}$ alloys become enriched in $\mathrm{Ni}$ as the $\mathrm{Cu}$-rich phase segregates during the hightemperature annealing treatments. Note that error bars would be included within the size of the symbols.

percentage, the amount of $\mathrm{Cu}$-rich phase is smaller (e.g., only $10 \%$ in $\mathrm{Ni}_{0.88} \mathrm{Cu}_{0.12}$ after annealing at $\left.\mathrm{T}_{\mathrm{ANN}}=625 \mathrm{~K}\right)$.

Further insight into the role of $\mathrm{Cu}$ on the thermally driven structural changes of electroplated $n c \mathrm{Ni}_{1-x} \mathrm{Cu}_{x}$ films was obtained by TEM. As shown in Figure 4, pronounced grain coarsening occurs in $\mathrm{Ni}_{0.56} \mathrm{Cu}_{0.44}$ after annealing at $625 \mathrm{~K}$ (cf. panels a and b), in agreement with XRD results. Remarkably, although large amounts of intragranular nanotwins are observed in the as-deposited film (panel c), most of these nanotwins are annihilated during annealing. Just a few, but larger, twinned regions (the so-called annealing twins) are perceptible after the heat-treatments, like the one indicated with a white arrow in panel $b$. The occurrence of growth nanotwins in $n c \mathrm{Cu}$ and $n c \mathrm{Ni}$ has been occasionally reported in the literature ${ }^{49,50}$ and is mainly ascribed to the low stacking fault energy of these metals, which favors the presence of these planar defects, giving rise to the anomalous peak broadening of the XRD peaks. Indeed, it has been reported that the stacking fault energy of $\mathrm{Ni}$ decreases by alloying with $\mathrm{Cu},{ }^{51}$ thus promoting the occurrence of planar defects. In addition, saccharine increases the probability of twinning in some electrodeposits (e.g., $\mathrm{Ni}$ ) because of its preferential adsorption onto (111) planes, resulting in an increased amount of crystal mass in twin orientation. ${ }^{52}$

High-resolution TEM imaging also provides evidence for $\mathrm{Cu}$ segregation at the grain boundaries of annealed $\mathrm{Ni}_{1-x} \mathrm{Cu}_{x}$ films. Panel d in Figure 4 shows a detail of a grain boundary (and the two surrounding grains) of the $\mathrm{Ni}_{0.56} \mathrm{Cu}_{0.44}$ film after annealing at $625 \mathrm{~K}$. Interestingly, the fast Fourier transform (FFT) of this micrograph [panel f] shows the occurrence of a double spot, with a slightly different interatomic spacing, at the position of the $\{111\}$ ring. Note that double spots are not observed in the FFT image of the as-deposited film [panel e], where only one interatomic distance is distinguished. Detailed analysis using FFT of selected regions of panel d (see Figure 5) indicate that the double spot only appears in regions that include the grain boundary (GB1 and GB2), whereas single spots with $d_{111} \approx$ $0.2038 \mathrm{~nm}$ are observed in the FFT of grains 1 and 2 (denoted as
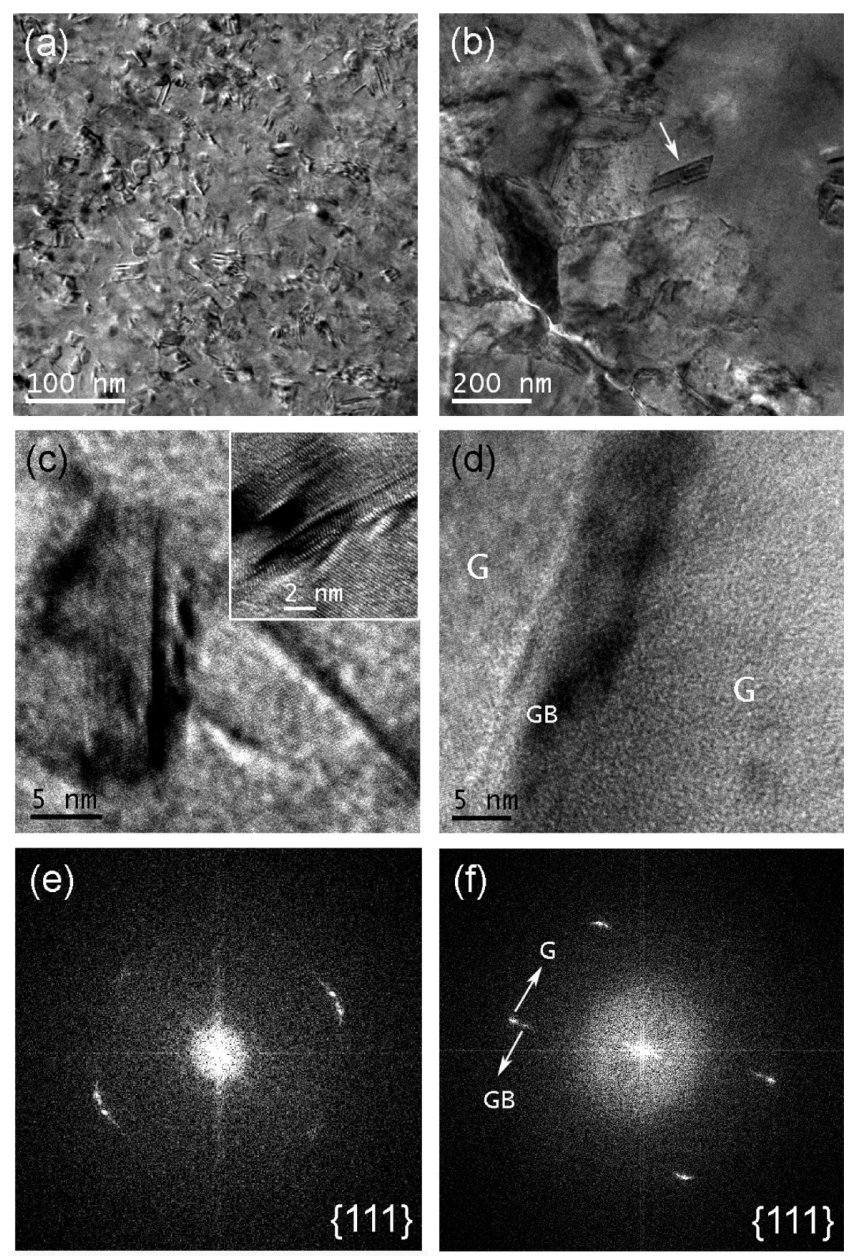

Figure 4. (a) Transmission electron microscopy (TEM) image of the as-deposited $\mathrm{Ni}_{0.56} \mathrm{Cu}_{0.44}$ alloy, revealing the nanocrystalline nature of the electroplated film; (b) TEM image of the same film after annealing at $T_{\mathrm{ANN}}=625 \mathrm{~K}$, where a pronounced increase in the average crystallite size is clearly observed (a few annealing twins are also observed, one of them is indicated with an arrow); (c) high resolution TEM image of the as-deposited $\mathrm{Ni}_{0.56} \mathrm{Cu}_{0.44}$ film, showing the presence of several intragranular nanotwins (as also evidenced in the inset, which corresponds to a different grain of the same film); (d) high-resolution TEM image of the $\mathrm{Ni}_{0.56} \mathrm{Cu}_{0.44}$ film annealed at $T_{\text {ANN }}=625 \mathrm{~K}$, showing a detail of a grain boundary; (e) fast-Fourier transform (FFT) of the image displayed in panel $c-$ the ring portion corresponds to the $\{111\}$ planes; (f) FFT of the image shown in panel $\mathrm{d}$. In the latter, a double peak is observed at the position of the $\{111\}$ planes. The spots located at a slightly larger interplanar distance correspond to the grain boundary (GB), whereas the other spots correspond to the interplanar distances in the grains $(G)$. This can be demonstrated by creating the inverse Fourier transform images from the FFT (see the Supporting Information for details).

G1 and G2). The emerging small inner spots in FFT of the grain boundary correspond to a slightly larger interplanar distance $\left(d_{111} \approx 0.2085 \mathrm{~nm}\right)$, indicating that the grain boundary region is enriched in $\mathrm{Cu}$ which, as previously stated, displays a larger cell parameter than $\mathrm{Ni}$. In order to confirm the $\mathrm{Cu}$ segregation, EELS analysis was also carried out. Elemental $\mathrm{Cu}$ and $\mathrm{Ni}$ quantification was performed following a line crossing a grain boundary, as indicated with the white arrow in Figure 6a. The EELS results clearly show that an increase in the Cu percentage (up to 82 at \% $\mathrm{Cu}$ ) occurs at the grain boundaries during annealing of the 


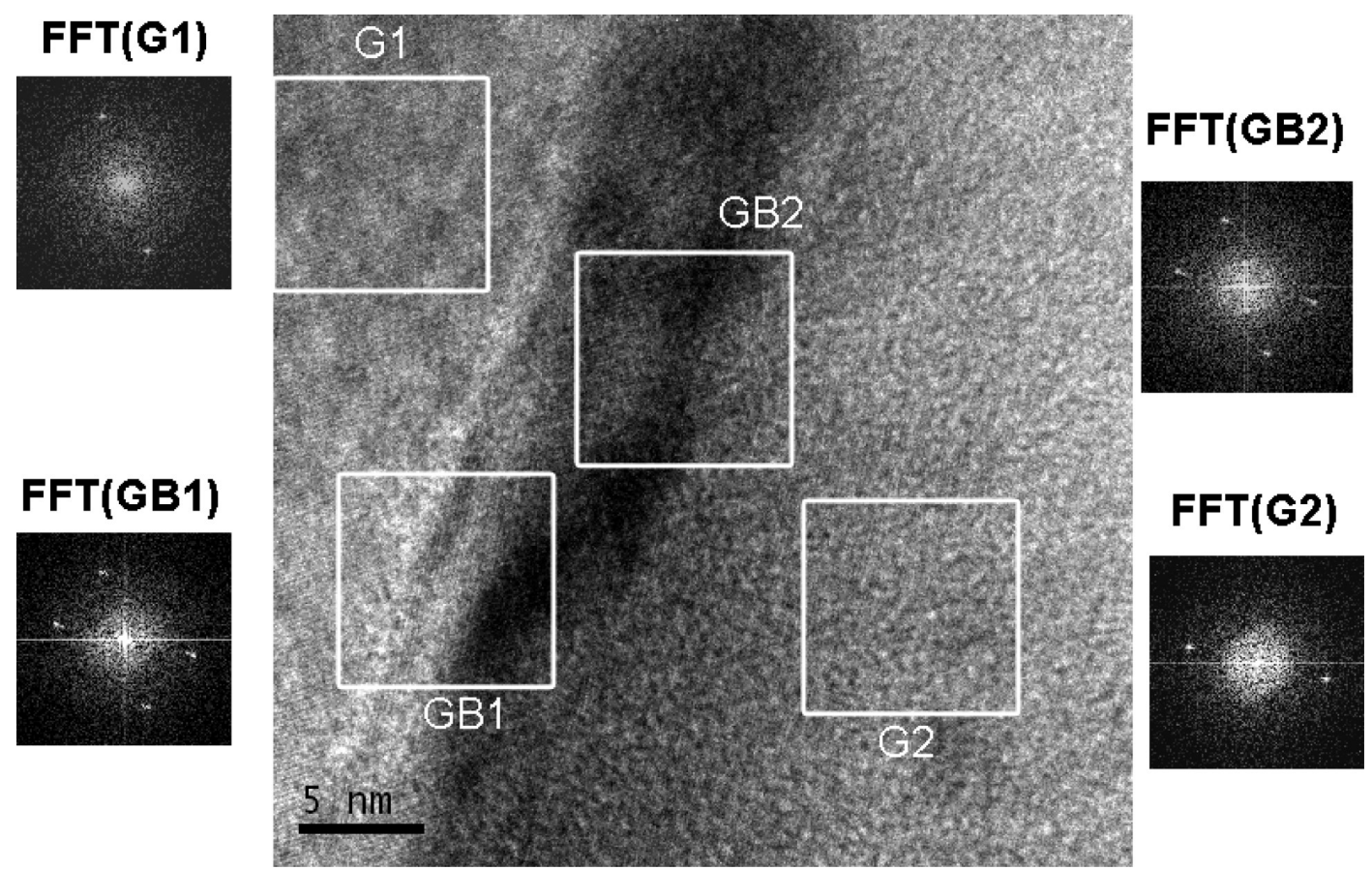

Figure 5. (a) Transmission electron microscopy (TEM) image of the $\mathrm{Ni}_{0.56} \mathrm{Cu}_{0.44}$ film annealed at $T_{\mathrm{ANN}}=625 \mathrm{~K}$, together with fast Fourier Transform (FFT) images of selected regions of the film. Remarkably, the FFT analyses corresponding to grain 1 (G1) and grain (G2) feature single spots located at the $\{111\}$ interplanar distance $\left(d_{111} \approx 0.2038 \mathrm{~nm}\right)$. Conversely, double-spots are clearly observed in FFT images GB1 and GB2, which correspond to the grain boundary region and include portions of grains 1 and 2. In particular, the emerging small inner spots in FFT(GB1) and FFT(GB2) correspond to a slightly larger interplanar distance, $d_{111} \approx 0.2085 \mathrm{~nm}$, indicating that the grain boundary region is enriched in $\mathrm{Cu}$.
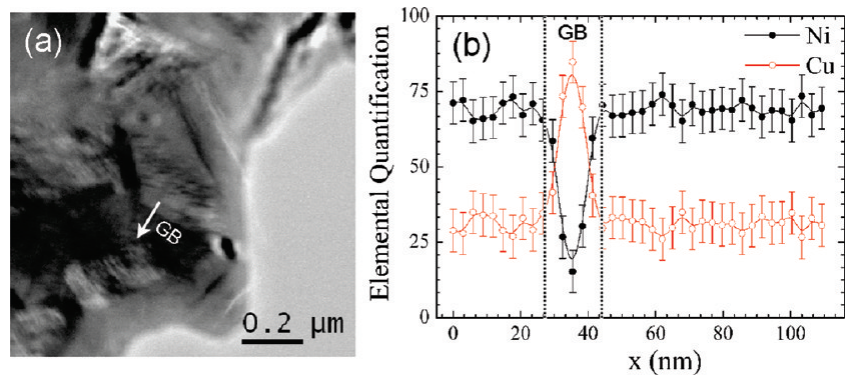

Figure 6. (a) Bright-field scanning transmission electron microscopy image of the $\mathrm{Ni}_{0.56} \mathrm{Cu}_{0.44}$ film annealed at $T_{\mathrm{ANN}}=625 \mathrm{~K}$; (b) elemental quantification (at\% $\mathrm{Ni}$ and $\mathrm{Cu}$ ), using electron energy loss spectroscopy EELS, following the white arrow highlighted in a, which traverses a grain boundary (GB) region. The EELS analysis reveals that the GB region is a $\mathrm{Cu}$-rich $\mathrm{Ni}-\mathrm{Cu}$ solid solution, whereas the composition of the surrounding grains is concurrently depleted in $\mathrm{Cu}$, indicating $\mathrm{Cu}$ grain boundary segregation.

$\mathrm{Ni}_{0.56} \mathrm{Cu}_{0.44}$ film. Concomitantly, the surrounding grains become overall depleted in $\mathrm{Cu}$ and a nominal composition around $\mathrm{Ni}_{0.73} \mathrm{Cu}_{0.27}$ is obtained inside the grains. It is worth noting that copper diffusion appears to be enhanced with respect to the diffusion in bulk, likely as a consequence of the presence of defects in the films. It has been reported that the diffusion coefficient of $\mathrm{Cu}$ strongly depends on the density of dislocations, so that the transport in dislocated samples is much faster than in a virtually defect-free material. ${ }^{53,54}$ This agrees rather well with the changes observed in the cell parameter during annealing (Figure 3), where the $a$ value of $\mathrm{Ni}_{0.56} \mathrm{Cu}_{0.44}$ after annealing at $T_{\mathrm{ANN}}=625 \mathrm{~K}$ resembles that of as-deposited $\mathrm{Ni}_{0.70} \mathrm{Cu}_{0.30}$ film.
Grain boundary segregation can be understood in terms of the cohesive energy of $\mathrm{Ni}$ and $\mathrm{Cu}$. During annealing, more bonds are broken at the grain boundaries than in the interior of grains. Hence, elements with lower cohesive energy tend to concentrate/ accumulate along the grain boundaries. Because the cohesive energy of $\mathrm{Ni}(4.44 \mathrm{eV})$ is larger than for $\mathrm{Cu}(3.49 \mathrm{eV}),{ }^{55} \mathrm{Cu}$ atoms are more likely to concentrate on grain boundaries than $\mathrm{Ni}$ atoms. This phenomenon is similar to what has been observed in the $\mathrm{Fe}-\mathrm{Cu}$ system, where $\mathrm{Cu}$ atoms also accumulate at grain boundaries and cause an increase in the thermal stability of the alloy. ${ }^{16}$ Such effect has also been observed in electrodeposited fcc $\mathrm{Ni}-\mathrm{Fe}$ alloys, where alloying of $\mathrm{Fe}$ with $\mathrm{Ni}$ was reported to bring about changes in both grain boundary composition and structure, which were ultimately responsible for the higher thermal stability of $\mathrm{Fe}-\mathrm{Ni}$ compared to pure $\mathrm{Ni}^{56,58}$ In the case of $\mathrm{Ni}-\mathrm{P}$ alloys (either electrodeposited or electroless-plated), both grain boundary solute drag and Zener drag $\left(\mathrm{Ni}_{3} \mathrm{P}\right.$ precipitates $)$ account for the enhanced thermal stability. ${ }^{58,59}$ Nevertheless, sometimes the presence of impurities plays also a large effect on the thermal stability of the electrodeposits. ${ }^{60}$

It should be noted that atomic $\mathrm{Cu}$ interdiffusion from the seed layer toward the upper $\mathrm{Ni}_{1-x} \mathrm{Cu}_{x}$ films would also preferably occur by atomic motions through the grain boundaries since the atomic mobility at grain boundaries is larger than inside the grains. Indeed, the activation energy for bulk diffusion of $\mathrm{Cu}$ into $\mathrm{Ni}(297 \mathrm{~kJ} / \mathrm{mol})^{61}$ is much larger than for $\mathrm{Cu}$ migration through $\mathrm{Ni}$ grain boundaries $(124 \mathrm{~kJ} / \mathrm{mol}){ }^{62}$ Hence, interdiffusion from the $\mathrm{Cu}$ seed layer would also contribute to the observed $\mathrm{Cu}$ enrichment at the $\mathrm{Ni}_{0.56} \mathrm{Cu}_{0.44}$ grain boundaries.

The beneficial effect of $\mathrm{Cu}$ enrichment at grain boundaries on the thermal stability of the $\mathrm{Ni}_{1-\mathrm{x}} \mathrm{Cu}_{x}$ system can be understood as 


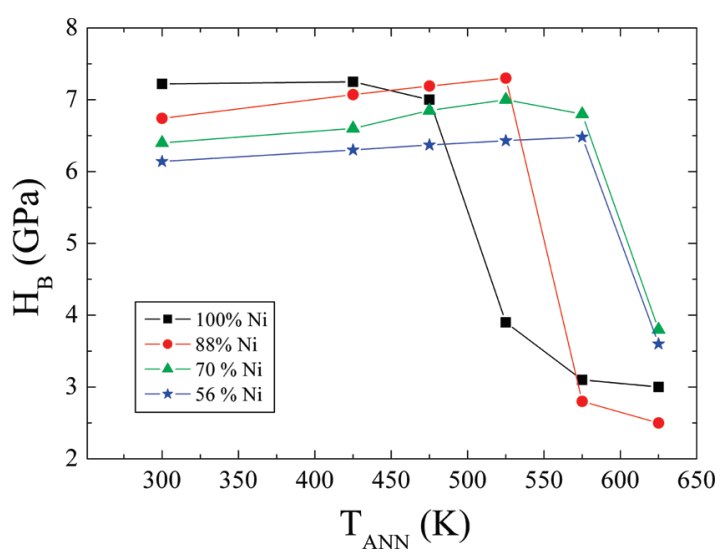

Figure 7. Dependence of Berkovich hardness, $\mathrm{H}_{\mathrm{B}}$, on the annealing temperature, $\mathrm{T}_{\mathrm{ANN}}$, for pure $\mathrm{Ni}$ (black square), $\mathrm{Ni}_{0.88} \mathrm{Cu}_{0.12}$ (red circle), $\mathrm{Ni}_{0.70} \mathrm{Cu}_{0.30}$ (green triangle), and $\mathrm{Ni}_{0.56} \mathrm{Cu}_{0.44}$ (blue star) films. After annealing, $H_{\mathrm{B}}$ slightly increases for low annealing temperatures (because of the grain boundary relaxation). However, at sufficiently large $T_{\text {ANN }}$ values, $\mathrm{H}_{\mathrm{B}}$ significantly decreases owing to grain growth. Note that whereas for pure $\mathrm{Ni}, H_{\mathrm{B}}$ decreases already after heating to $525 \mathrm{~K}$, for the $\mathrm{Ni}_{0.70} \mathrm{Cu}_{0.30}$ and $\mathrm{Ni}_{0.56} \mathrm{Cu}_{0.44}$ films, $H_{\mathrm{B}}$ does not fall until $T_{\mathrm{ANN}}=625 \mathrm{~K}$. Note that error bars would be included within the size of the symbols.

follows. When temperature is sufficiently raised, grain growth is accompanied by an elimination of grain boundaries, implying that, to a certain extent, $\mathrm{Cu}$ atoms have to be redissolved into the $\mathrm{Ni}$-rich $\mathrm{Ni}_{1-x} \mathrm{Cu}_{x}$ grains. However, this is energetically unfavorable because the enthalpy of mixing between $\mathrm{Ni}$ and $\mathrm{Cu}$ is positive (with maximum values ranging between +0.5 to $+1.5 \mathrm{~kJ}$ / mol). ${ }^{63-65}$ In pure Ni films, because $\mathrm{Cu}$ grain boundary segregation does not take place, grain growth readily occurs at $T_{\mathrm{ANN}}=$ $475 \mathrm{~K}$. However, in $\mathrm{Ni}_{1-x} \mathrm{Cu}_{x}$ films, and for annealing temperatures beyond $475 \mathrm{~K}$, there is a competition between thermally driven $\mathrm{Cu}$ segregation and the tendency for grain coarsening and, as a result, grain growth is inhibited until enough energy is supplied to the system. Note that in pure $\mathrm{Ni}$ films, $\mathrm{Cu}$ diffusion from the seed-layer, which could also hinder grain coarsening, occurs only at higher annealing temperatures $\left(T_{\mathrm{ANN}}=625 \mathrm{~K}\right)$, once the Ni grains have already grown. Since the enthalpy of mixing between $\mathrm{Ni}$ and $\mathrm{Cu}$ for $\mathrm{Ni}$-rich alloys is only slightly positive, thermal annealing is not found to cause precipitation of $\mathrm{Cu}$ nanoparticles (at least for the investigated range of temperatures). This is opposite to what occurs in other systems, like $\mathrm{Fe}-\mathrm{Cu}$, where the large positive enthalpy of mixing $(+13 \mathrm{~kJ} /$ mol) promotes annealing-induced phase separation. ${ }^{16}$

Mechanical and Magnetic Properties of As-Prepared and Annealed Films. The aforementioned thermally induced structural changes occurring in $\mathrm{Ni}_{1-\mathrm{x}} \mathrm{Cu}_{x}$ films cause a significant effect on the resulting mechanical and magnetic properties. The overall dependence of the Berkovich indentation hardness, $\mathrm{H}_{\mathrm{B}}$, on $\mathrm{T}_{\mathrm{ANN}}$ for the different film compositions is plotted in Figure 7. The hardness of the as-deposited films decreases as the $\mathrm{Cu}$ content is increased, from 7.21 GPa (for $x=0$ ) to $6.15 \mathrm{GPa}$ (for $x=0.44$ ). The hardness of pure $\mathrm{Ni}$ in the as-prepared state resembles the values reported in the literature for electrodeposited $n c \mathrm{Ni}$ when evaluated by nanoindentation, ${ }^{66}$ but it is slightly larger than those obtained by conventional Vickers measurements. ${ }^{67,68}$ This can be explained on the basis of the indentation size effect. Typically, due to strain gradient hardening, the hardness values estimated at low loads can be as much as 10 to $30 \%$ larger than the hardness that would be obtained for sufficiently large loads. In addition, even for comparable crystallize sizes, other effects such as impurity contents (e.g., sulfur), dissimilar degrees of porosity or residual stress can also affect the hardness, thus accounting for the dispersion in the values one can find in the literature. ${ }^{69}$ It should be noted that the hardness values obtained in the $n c \mathrm{Ni}_{1-x} \mathrm{Cu}_{x}$ thin films investigated here are larger than those of microcrystalline or $n c \mathrm{Cu}$ thin films, ${ }^{70}$ which is not surprising bearing in mind that $\mathrm{Ni}$ is intrinsically harder than $\mathrm{Cu} .{ }^{71}$ However, the hardness of the $n c \mathrm{Ni}_{1-x} \mathrm{Cu}_{x}$ films is also considerably larger than the values in electrodeposited fine-grained pure $\mathrm{Ni}^{72}$ as-deposited $n c$ $\mathrm{Ni}-\mathrm{P}$ or $\mathrm{Ni}-\mathrm{Cu}-\mathrm{P}$ films, ${ }^{73}$ coarse-grained $\mathrm{Co}-\mathrm{Ni}$ alloys ${ }^{74}$ or $\mathrm{Ni}-\mathrm{P}-\mathrm{W}$ multilayered structures. ${ }^{75}$ Hence, it is clear that not only the composition but also the microstructure plays a crucial role on the mechanical properties of the investigated materials. In particular, the main reason for the large $H_{\mathrm{B}}$ displayed by the electrodeposited $\mathrm{Ni}_{1-x} \mathrm{Cu}_{x}$ alloys is the saccharine-assisted crystallite size refinement during thin film growth. For small crystallite sizes, the role of grain boundaries in hindering dislocation motion is enhanced, resulting in an increase of stress concentration due to dislocation pile-up. This leads to the well-known Hall-Petch relationship, which postulates that the hardness is inversely proportional to the square root of grain size. ${ }^{76}$ Intragranular nanotwins, like the ones shown in Figure 4c, also contribute to increase the hardness since twin boundaries can be considered analogous to high-angle grain boundaries in terms of disrupting dislocation motion. ${ }^{77}$

For certain applications of metallic thin films (e.g., wear resistant surface coatings or some MEMS/NEMS components like cantilevers, springs or microgears) it is desirable not only to prepare mechanically hard materials but also to be able to maintain these outstanding mechanical properties on usage and when eventually exposed to intermediate working temperatures. Figure 7 reveals that addition of $\mathrm{Cu}$ increases the temperature range within which $n c \mathrm{Ni}_{1-x} \mathrm{Cu}_{x}$ films exhibit large $\mathrm{H}_{\mathrm{B}}$ values. Indeed, although $\mathrm{H}_{\mathrm{B}}$ abruptly decreases in pure $n c \mathrm{Ni}$ films for $T_{\mathrm{ANN}}>475 \mathrm{~K}$, such a decrease occurs at much higher temperatures for $\mathrm{Ni}_{1-x} \mathrm{Cu}_{x}$ with $x=0.30$ or 0.44 . This can be mostly attributed to the different temperature interval where grain coarsening occurs in the series of investigated alloys (see Figure 2). The reduced Young's modulus, $E_{\mathrm{r}}$, does not show pronounced variations as a function of temperature. The $E_{r}$ values in as-deposited films range from $182 \mathrm{GPa}$ (for $x=0$ ) to $170 \mathrm{GPa}$ (for $x=0.44$ ) and slightly increase, by less than $10 \%$, as $T_{\mathrm{ANN}}$ is raised.

Another interesting observation, also from Figure 7, is that for all $\mathrm{Ni}_{1-x} \mathrm{Cu}_{x}$ films $H_{\mathrm{B}}$ slightly increases when the samples are annealed at relatively low temperatures. For example, $H_{\mathrm{B}}$ increases from 6.75 to $7.30 \mathrm{GPa}$ when the $\mathrm{Ni}_{0.88} \mathrm{Cu}_{0.22}$ alloy is annealed at $525 \mathrm{~K}$, hence slightly surpassing the hardness of asdeposited $n c \mathrm{Ni}$. Note that this behavior is opposite to the one conventionally observed in metals, where annealing typically lowers material strength. However, an increase in hardness for low annealing temperatures has been occasionally encountered in some $n c$ metallic systems prepared by electrodeposition or severe plastic deformation. ${ }^{78-80}$ It has been argued that thermal annealing can lead to strengthening of $n c$ metals because of structural relaxation of the nonequilibrium grain boundaries and a consequent depletion of available dislocation sources. Namely, as temperature is raised and the amount of microstrains decreases (see Figure $2 \mathrm{~b}$ ) it becomes progressively more difficult for such relaxed grain boundaries to emit dislocations under stress 

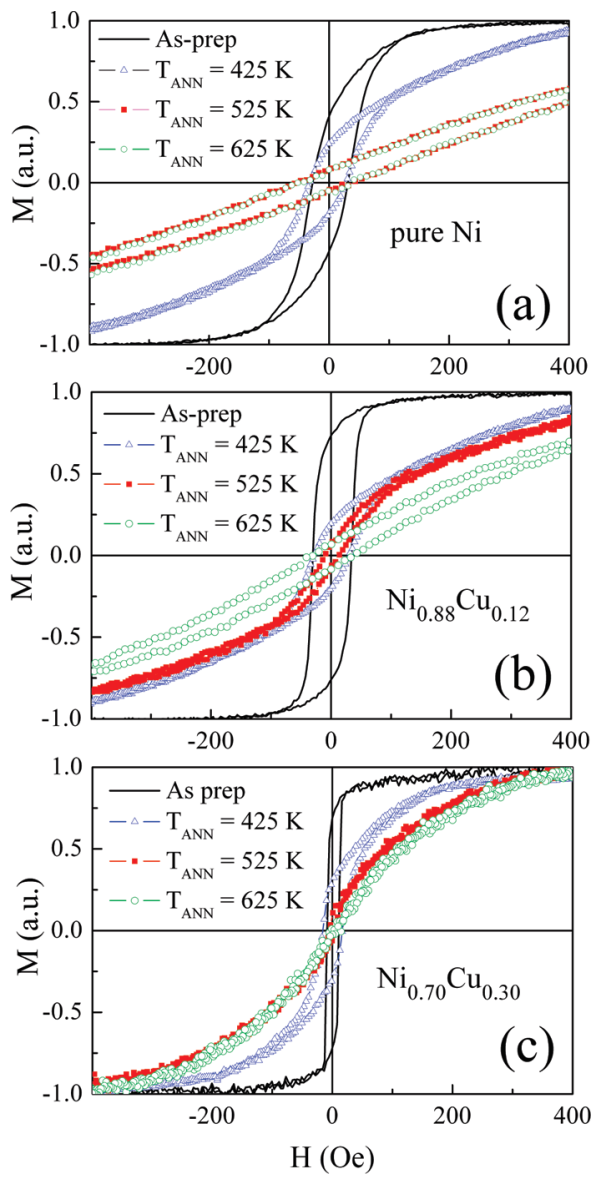

Figure 8. Hysteresis loops, measured in longitudinal configuration by magneto-optic Kerr effect, corresponding to (a) pure $\mathrm{Ni}$, (b) $\mathrm{Ni}_{0.88} \mathrm{Cu}_{0.12}$, and (c) $\mathrm{Ni}_{0.70} \mathrm{Cu}_{0.30}$ films, in the as-deposited states (black line) and after annealing at $T_{\mathrm{ANN}}=425 \mathrm{~K}$ (blue triangle), $\mathrm{T}_{\mathrm{ANN}}=$ $525 \mathrm{~K}$ (red square) and $T_{\mathrm{ANN}}=625 \mathrm{~K}$ (green circle). An obvious change in the magnetic properties is observed at relatively low annealing temperatures.

application, thus making the material more resistant to yielding. Thus, from our results it is clear that, in order to maximize hardness, it is ideal to achieve a $n c$ material whose grain boundaries are virtually free from microstrains.

The magnetic behavior of the $\mathrm{Ni}_{1-x} \mathrm{Cu}_{x}$ films is also markedly dependent on the annealing temperature. First, it is worth mentioning that only the samples with $x \leq 0.30$ are ferromagnetic at room temperature. Due to its large $\mathrm{Cu}$ content, the $\mathrm{Ni}_{0.56} \mathrm{Cu}_{0.44}$ alloy is paramagnetic, in agreement with the magnetic phase diagram reported in the literature for the $\mathrm{Ni}-\mathrm{Cu}$ system. 81,82 As shown in Figure 8, the hysteresis loops of the remaining Ni-rich $\mathrm{Ni}_{1-x} \mathrm{Cu}_{x}$ films become progressively more tilted as $\mathrm{T}_{\mathrm{ANN}}$ is increased. Remarkably, for the three compositions investigated here, a drastic variation in the shape of the loops occurs already at $T_{\mathrm{ANN}}=425 \mathrm{~K}$, even though the structural modifications at this low annealing temperature are scarce (see Figures 2 and 3). Particularly noticeable is the reduction in the remanence to saturation magnetization ratio, $M_{\mathrm{R}} / M_{\mathrm{S}}$, plotted in Figure $9 \mathrm{a}$ as a function of $T_{\mathrm{ANN}}$. The rapid decrease of $M_{\mathrm{R}} / M_{\mathrm{S}}$ with $T_{\mathrm{ANN}}$ is probably linked to the release of microstrains and the concomitant decrease of the domain wall energy, thus favoring self-demagnetizing effects, similar to
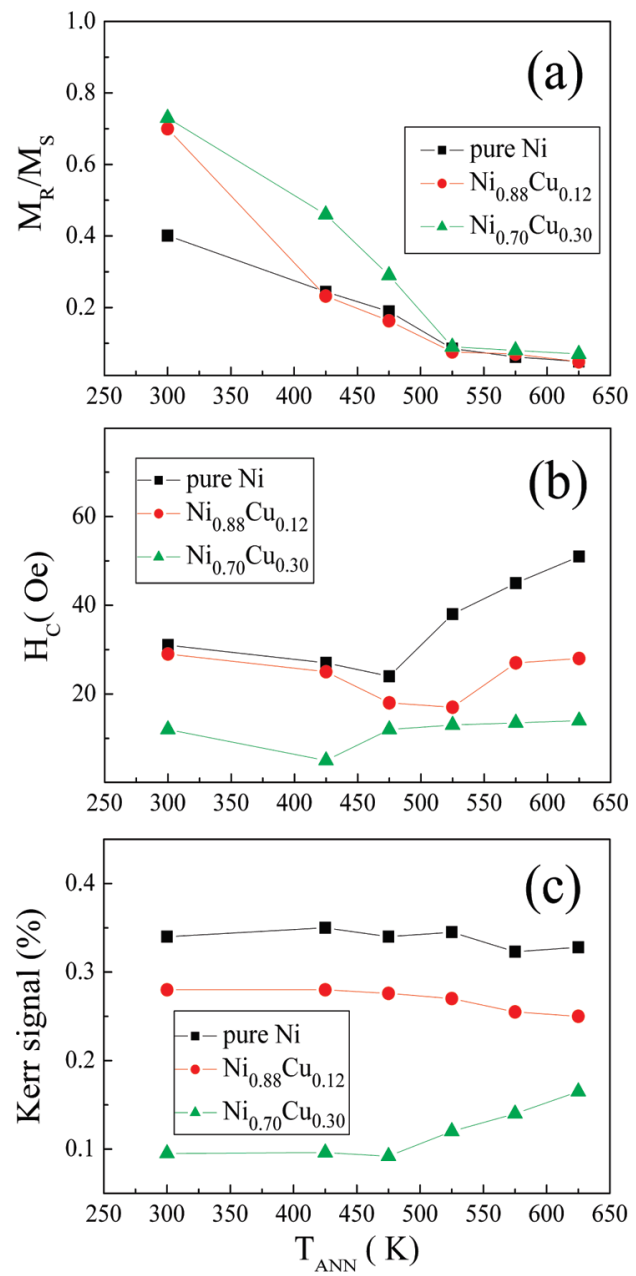

Figure 9. Dependence of (a) the remanence to saturation ratio, $M_{R} /$ $\mathrm{M}_{\mathrm{S}}$, (b) the coercivity, $\mathrm{H}_{\mathrm{C}}$, and (c) the overall Kerr signal (proportional to the saturation magnetization) of pure $\mathrm{Ni}$ (black triangle), $\mathrm{Ni}_{0.88} \mathrm{Cu}_{0.12}$ (red circle), and $\mathrm{Ni}_{0.70} \mathrm{Cu}_{0.30}$ (green triangle) films. Note that while $\mathrm{M}_{\mathrm{R}}$ / $\mathrm{M}_{\mathrm{S}}$ decreases with $T_{\mathrm{ANN}}$ (because of the decrease in microstrains), $\mathrm{H}_{\mathrm{C}}$ tends to increase for $T_{\mathrm{ANN}}>475 \mathrm{~K}$, probably because of the grain coarsening and the formation of the nonmagnetic $\mathrm{Cu}$-rich phase, which tends to isolate ferromagnetic $\mathrm{Ni}_{1-x} \mathrm{Cu}_{x}$ grains, thus reducing magnetic dipolar interactions. Note that error bars would be included within the size of the symbols.

what has been reported for permalloy annealed at intermediate temperatures. $^{83}$

In turn, the coercivity, $H_{\mathrm{C}}$, of the as-deposited films is lower for larger $\mathrm{Cu}$ contents. This cannot be attributed solely to variations in the crystallite size, as $\langle\mathrm{D}\rangle$ is virtually independent of the composition of the films (Figure 2). Hence, changes in $\mathrm{H}_{\mathrm{C}}$ are probably related to variations in the magnetocrystalline anisotropy. In fact, the magnetocrystalline anisotropy in the $\mathrm{Ni}-\mathrm{Cu}$ system has been reported to increase with the Ni percentage. ${ }^{84}$ Furthermore, for Ni contents around 70 at \% the Curie temperature should be close to room temperature, ${ }^{82}$ which should further reduce the anisotropy. In any case, such reduced coercivity values, achieved by $\mathrm{Cu}$ alloying, are desirable in soft-magnetic micro/nanocomponents. Figure $9 \mathrm{~b}$ shows that $H_{\mathrm{C}}$ tends to increase for $T_{\text {ANN }} \geq 475 \mathrm{~K}$. This effect is probably related to the $\mathrm{Cu}$ grain boundary segregation since the emerging $\mathrm{Cu}$ rich interfacial phase is paramagnetic at room temperature 
and, therefore, it tends to isolate the ferromagnetic $\mathrm{Ni}_{1-x} \mathrm{Cu}_{x}$ grains, thus reducing intergranular magnetic exchange interactions which are often detrimental in terms of coercivity. Finally, the overall Kerr signal, which is proportional to the surface saturation magnetization of the $\mathrm{Ni}_{1-x} \mathrm{Cu}_{x}$ films, does not show pronounced variations as a function of $T_{\mathrm{ANN}}$, except for the $\mathrm{Ni}_{0.70} \mathrm{Cu}_{0.30}$ film, where an increase is observed for $T_{\mathrm{ANN}}>475 \mathrm{~K}$ (see Figure 9c). This has several implications. On the one hand, the result suggests that intermixing between the $\mathrm{Cu}$ seed layer and the $\mathrm{Ni}_{1-x} \mathrm{Cu}_{x}$ films does not extend throughout the overall film thickness (otherwise a reduction in the Kerr signal would be observed at high $T_{\mathrm{ANN}}$ values in pure Ni films). On the other hand, the increase in Kerr signal in the $\mathrm{Ni}_{0.70} \mathrm{Cu}_{0.30}$ film indicates that for this particular composition, the $\mathrm{Ni}$-enrichment inside the grains, resulting from $\mathrm{Cu}$ grain boundary segregation (as evidenced by EELS), surpasses the loss of magnetization which stems from the thermally induced formation of the interfacial paramagnetic phase.

\section{CONCLUSIONS}

In summary, our work demonstrates that the thermal stability of electroplated $n c \mathrm{Ni}$ becomes considerably enhanced when $\mathrm{Cu}$ is added to the system to form a $\mathrm{Ni}-\mathrm{Cu}$ solid solution. The composition of the $\mathrm{Ni}-\mathrm{Cu}$ alloys can be precisely tailored by changing the applied current density during electrodeposition. The improved thermal stability is mainly ascribed to $\mathrm{Cu}$ grain boundary segregation that occurs during annealing. Because $\mathrm{Ni}$ and $\mathrm{Cu}$ have a positive enthalpy of mixing, the segregated $\mathrm{Cu}$-rich layer stabilizes the $n c$ structure against thermally induced grain growth. As a consequence, the mechanical and some magnetic properties of $\mathrm{Ni}_{1-x} \mathrm{Cu}_{x}$ annealed films (for $x=0.30$ or 0.44 ) are superior to those of annealed $\mathrm{Ni}$. These results, apart from their fundamental interest, are also of technological relevance for the implementation of nanocrystalline metallic films in high-temperature applications. The electrochemically controlled alloying of metallic species with positive enthalpy of mixing can pave the way to enhance the functionality of $n c$ metallic films for a wide variety of assorted purposes.

\section{ASSOCIATED CONTENT}

S Supporting Information. High-resolution transmission electron microscopy (TEM) image and Fourier transform (FFT) imageof the $\mathrm{Ni}_{0.56} \mathrm{Cu}_{0.44}$ film annealed at $T_{\text {ANN }}=625 \mathrm{~K}(\mathrm{PDF})$. This material is available free of charge via the Internet at http://pubs.acs.org/.

\section{AUTHOR INFORMATION}

\section{Corresponding Author}

*Phone: +003493 5811401. Fax: +0034935812155. E-mail: eva. pellicer.icn@uab.cat (E.P.); jordi.sort@uab.cat (J.S.).

\section{ACKNOWLEDGMENT}

The authors thank the Servei de Microscòpia of the Universitat Autònoma de Barcelona and the Serveis Cientifico-Tècnics of the Universitat de Barcelona for the technical assistance during TEM and EELS characterization. We also acknowledge the Spanish MICINN (MAT2007-61629 and MAT2010-20616C02) and the Catalan DGR (2009-SGR-1292) for partial financial support. E.P. is indebted to the Generalitat de Catalunya for the Beatriu de Pinós postdoctoral fellowship. M.D.B. acknowledges partial financial support from an ICREA-Academia Award.

\section{REFERENCES}

(1) Gleiter, H. Acta Mater. 2000, 48, 1-29.

(2) McFadden, S. X.; Mishra, R. S.; Valiev, R. Z.; Zhilyaev, A. P.; Mukherjee, A. K. Nature 1999, 398, 684-686.

(3) Lu, K.; Lu, L; Suresh, S. Science 2009, 324, 349-352.

(4) Rajagopalan, J.; Han, J. H.; Saif, M. T. A. Science 2007, 315, $1831-1834$.

(5) Zorman, C. A.; Mehregany, M. Springer Handbook of Nanotechnology, Part A; Bhushan, B., Ed.; Sringer-Verlag: Berlin, 2010; Chapter 11.

(6) Luber, E.; Mohammadi, R; Ophus, C.; Lee, Z.; Nelson-Fitzpatrick, N.; Westra, K.; Evoy, S.; Dahmen, U.; Radmilovic, V.; Mitlin, D. Nanotechnology 2008, 19, 125705.

(7) Baghbanan, M.; Erb, U.; Palumbo, G. Phys. Status Solidi A 2006, 203, 1259-1264.

(8) Andrievski, R. A. J. Mater. Sci. 2003, 38, 1367-1375.

(9) Krill, C. E.; Ehrhardt, H.; Birringer, R. Z. Metallkund. 2005, 96, 1134-1141.

(10) Kirchheim, R. Acta Mater. 2002, 50, 413-419.

(11) Darling, K. A.; VanLeeuwen, B. K.; Koch, C. C.; Scattergood, R. O. Mater. Sci. Eng., A 2010, 527, 3572-3580.

(12) Färber, B.; Cadel, E.; Menand, A.; Schmitz, G.; Kirchheim, R. Acta Mater. 2000, 48, 789-796.

(13) Weissmüller, J.; Krauss, W.; Haubold, T.; Birringer, R.; Gleiter, H. Nanostruct. Mater. 1992, 1, 439-447.

(14) VanLeeuwen, B. K.; Darling, K. A.; Koch, C. C.; Scattergood, R. O.; Butler, B. G. Acta Mater. 2010, 58, 4292-4297.

(15) Talin, A. A.; Marquis, E. A.; Goods, S. H.; Kelly, J. J.; Miller, M. K. Acta Mater. 2006, 54, 1935-1947.

(16) Eckert, J.; Holzer, J. C.; Johnson, W. L. J. Appl. Phys. 1993, $73,131-141$.

(17) Liu, F. Mater. Lett. 2005, 59, 1458-1462.

(18) Michels, A.; Krill, C. E.; Ehrhardt, H.; Birringer, R.; Wu, D. T. Acta Mater. 1999, 47, 2143-2152.

(19) Detor, A. J.; Schuh, C. A. Acta Mater. 2007, 55, 4221-4232.

(20) Schlesinger, M.; Paunovic, M. Modern Electroplating; John Wiley \& Sons: New York, 2000.

(21) Bicelli, L. P.; Bozzini, B.; Mele, C.; D’Urzo, L. Int. J. Electrochem. Sci. 2008, 3, 356-408.

(22) Wang, F.; Hosoiri, K.; Doi, S.; Okamoto, N.; Kuzushima, T.; Totsuka, T.; Watanabe, T. Electrochem. Commun. 2004, 6, 1149-1152.

(23) Gómez, E.; Pellicer, E.; Duch, M.; Esteve, J.; Vallés, E. Electrochim. Acta 2006, 51, 3214-3222.

(24) Klimenkov, M.; Haseeb, A. S. M. A.; Bade, K. Thin Solid Films 2009, 517, 6593.

(25) Zhang, Y.; Ivey, D. G. Chem. Mater. 2004, 16, 1189-1194.

(26) Song, Y.; Zhang, S.; Li, J.; Zhao, C.; Zhang, X. Acta Biomater. 2010, 6, 1736-1742.

(27) Bartlett, P. N.; Ghanem, M. A.; El Hallag, I. S.; de Groot, P.; Zhukov, A. J. Mater. Chem. 2003, 13, 2596-2602.

(28) Younes, O.; Zhu, L.; Rosenberg, Y.; Shacham-Diamand, Y.; Gileadi, E. Langmuir 2001, 17, 8270-8275.

(29) Pellicer, E.; Varea, A.; Pané, S.; Nelson, B. J.; Menéndez, E.; Estrader, M.; Suriñach, S.; Baró, M. D.; Nogués, J.; Sort, J. Adv. Funct. Mater. 2010, 20, 983-991.

(30) Bahlawane, N.; Premkumar, P. A.; Tian, Z.; Hong, X.; Qi, F.; Kohse-Höinghaus, K. Chem. Mater. 2010, 22, 92-100.

(31) Myung, N. V.; Park, D. Y.; Yoo, B. Y.; Sumodjo, P. T. A. J. Magn. Magn. Mater. 2003, 265, 189-198.

(32) Young, R. A. The Rietveld Method; International Union of Crystallography Monographs on Crystallography; Oxford University Press, Oxford, 1995.

(33) Morales, M.; Chateigner, D.; Lutterotti, L. Thin Solid Films 2009, 517, 6264-6270. 
(34) Warren, B. E. X-ray Diffraction; Addison-Wesley: Reading, MA, 1969

(35) Fischer-Cripps, A. C. Nanoindentation; Springer: New York, 2004.

(36) Oliver, W. C.; Pharr, G. M. J. Mater. Res. 1992, 7, 1564-1583.

(37) Sort, J.; Zhilyaev, A.; Zielinska, M.; Nogués, J.; Suriñach, S.; Thibault, J.; Baró, M. D. Acta Mater. 2003, 51, 6385-6393.

(38) Natter, H.; Schmelzer, M.; Hempelmann, R. J. Mater. Res. 1998, $13,1186-1197$.

(39) Boylan, K.; Ostrander, D.; Erb, U.; Palumbo, G.; Aust, K. T. Scr. Metall. Mater. 1991, 25, 2711-2716.

(40) Klement, U.; Erb, U.; El-Sherik, A. M.; Aust, K. T. Mater. Sci. Eng., A 1995, 203, 177-186.

(41) El-Sherik, A. M.; Boylan, K.; Erb, U.; Palumbo, G.; Aust, K. T. Mater. Res. Soc. Symp. Proc. 1992, 238, 727-732.

(42) Cziráki, A.; Tonkovics, Zs.; Geröcs, I.; Fogarassy, B.; Groma, I.; Tóth-Kádar, E.; Tarnóczi, T.; Bakonyi, I. Mater. Sci. Eng., A 1994, 179-180, 531-535.

(43) Iordache, M. C.; Whang, S. H.; Jiao, Z.; Wang, Z. M. Nanostruct. Mater. 1999, 11, 1343-1349.

(44) Thuvander, M.; Abraham, M.; Cerezo, A.; Smith, G. D. W. Mater. Sci. Technol. 2001, 17, 961-970.

(45) Yamamoto, Y.; Uemura, S.; Kajihara, M. Mater. Sci. Eng., A 2001, 312, 176-181.

(46) Wandelt, K.; Brundle, C. R. Phys. Rev. Lett. 1981, 46, 1529-1532.

(47) Abrikosov, I. A.; Skriver, H. L. Phys. Rev. B 1993, 47, 16532-16541.

(48) Ahmed, J.; Ramanujachary, K. V.; Lofland, S. E.; Furiato, A.; Gupta, G.; Shivaprasad, S. M.; Ganguli, A. K. Colloid. Surf. A 2008, $331,206-212$

(49) Randle, V. Acta Mater. 1999, 47, 4187-4196.

(50) Lu, L.; Chen, X.; Huang, X.; Lu, K. Science 2009, 323, 607-610.

(51) Ebrahimi, F.; Ahmed, Z.; Li, H. Appl. Phys. Lett. 2004, 85, 3749-3751.

(52) Velinov, V.; Vitkova, S.; Pangarov, P. Surf. Technol. 1977, 6, $19-29$.

(53) Barthula, M.; Aboelfotoh, M. O.; Meyer, F. Micro. Eng. 2001, $55,323-328$.

(54) Bracht, H.; Stolwijk, N. A.; Mehrer, H. Phys. Rev. B 1991, 43, 14465-14477.

(55) Philipsen, P. H. T.; Baerends, E. J. Phys. Rev. B 1996, 54, 5326-5333.

(56) Czerwinski, F.; Li, H.; Megret, M.; Szpunar, J. A. Scr. Mater. 1997, 37, 1967-1972.

(57) Li, H. Q.; Ebrahimi, F. Acta Mater. 2003, 51, 3905-3913.

(58) Gonzalez, F.; Brennenstuhl, A. M.; Palumbo, G.; Erb, U.; Lichtenberger, P. C. Mater. Sci. For. 1996, 83, 225-227.

(59) Mehta, S. C.; Smith, D. A.; Erb, U. Mater. Sci. Eng., A 1995, 204, 227-232.

(60) Hibbard, G. D.; Aust, K. T.; Erb, U. Mater. Sci. Eng., A 2006, 433, 195-202.

(61) Rasuli, R.; Zad, A. I.; Ahadian, M. M. Vacuum 2010, 84, 469-473.

(62) Kolobov, Y. R.; Grabovetskaya, G. P.; Ivanov, M. B.; Zhilyaev, A. P.; Valiev, R. Z. Scr. Mater. 2001, 44, 873-878.

(63) Abrikosov, I. A.; Skriver, H. L. Phys. Rev. B 1993, 47, $16532-16541$

(64) Lee, B. J.; Shim, J. H. Calphad 2004, 28, 125-132.

(65) Turchanin, M. A.; Agraval, P. G.; Abdulov, A. R. Powder Metall. Met. Ceram. 2007, 46, 467-477.

(66) Schwaiger, R.; Moser, B.; Dao, M.; Chollacoop, N.; Suresh, S. Acta Mater. 2003, 51, 5159-5172.

(67) Hughes, G. D.; Smith, S. D.; Pande, C. S.; Johnson, H. R.; Armstrong, R. W. Scripta Metall. 1986, 20, $93-97$.

(68) El-Sherik, A. M.; Erb, U.; Palumbo, G.; Aust, K. T. Scr. Metall. Mater. 1992, 27, 1185-1188.

(69) Koch, C. C.; Shen, T. D. in Processing and Properties of Nanocrystalline Materials; Suryanarayana, C. et al. , Eds.; The Minerals, Metals \& Materials Society: Warrendale, PA, 1996.
(70) Dao, M.; Lu, L.; Asaro, R. J.; De Hosson, J. T. M.; Ma, E. Acta Mater. 2007, 55, 4041-4065.

(71) Samsonov, G. V. Handbook of the Physicochemical Properties of the Elements; IFI-Plenum: New York, 1968.

(72) Lamovec, J.; Jović, V.; Randjelović, D.; Aleksić, R.; Radojević, V. Thin Solid Films 2008, 516, 8646-8654.

(73) Balaraju, J. N.; Rajam, K. S. Surf. Coat. Technol. 2005, 195, 154-161.

(74) Wang, L. P.; Gao, Y.; Xue, Q. J. Appl. Suf. Sci. 2005, 242, 326-332.

(75) Papachristos, V. D.; Panagopoulos, C. N.; Christoffersen, L. W.; Markaki, A. Thin Solid Films 2001, 396, 173-182.

(76) Dieter, G. E. Mechanical Metallurgy, 3rd ed.; McGraw-Hill Science/Engineering/Math: New York, 1986.

(77) Zhang, X.; Misra, A.; Wang, H.; Nastasi, M.; Embury, J. D.; Mitchell, T. E.; Hoagland, R. G.; Hirth, J. P. Appl. Phys. Lett. 2004, 84, 1096-1098.

(78) Valiev, R. Z.; Sergueeva, A. V.; Mukherjee, A. K. Scr. Mater. 2003, 49, 669-674.

(79) Wang, Y. M.; Cheng, S.; Wei, Q. M.; Ma, E.; Nieh, T. G.; Hamza, A. Scr. Mater. 2004, 51, 1023-1028.

(80) Huang, X.; Hansen, N.; Tsuji, N. Science 2006, 312, 249-251.

(81) Ahern, S. A.; Martin, M. J. C.; Sucksmith, W. Proc. R. Soc. London, Ser. A 1958, 248, 145-152.

(82) Ododo, J. C.; Coles, B. R. J. Phys. F: Met. Phys. 1977, 7, 2393-2400.

(83) Chikazumi, S. Physics of Magnetism; R. E. Krieger Publishing Company: Malabar, FL, 1978; Chapter 12.

(84) Booth, J. G.; Wijn, H. P. J.; Zibold, G. Numerical Data and Functional Relationships in Science and Technology; Landolt-Börnsteinin Wijn, H. P. J., Ed.; Springer-Verlag: Berlin, 1993; Vol. 19 (Magnetic Properties of Metals), SubVol. B. 